\title{
Castleman's Disease Combined with the Development of Systemic Lupus Erythematosus
}

\author{
Sistemik Lupus Eritematöz Gelişimi ile Birlikte Seyreden Castleman Hastalığ 1
}

\author{
Ying $\mathrm{HU},{ }^{1} \mathrm{Xian} \mathrm{ZHONG}^{2,3}$ \\ ${ }^{1}$ Department of Nephrology, The Second Affiliated Hospital, Zhejiang University College of Medicine, Hangzhou, China \\ ${ }^{2}$ The Second Affiliated Hospital (Binjiang Branch), Zhejiang University College of Medicine, Hangzhou, China; ${ }^{3}$ Hangzhou Bin-Jiang Hospital, China
}

We present the case of a 16-year-old boy who was admitted to our hospital with hair loss, mainly on the top of his head, which had been occurring for seven months and erythema on his face, which had begin two months prior to coming to our facility. The erythrocyte sedimentation rate (ESR) was $22 \mathrm{~mm} / \mathrm{h}$, and a urinalysis showed a urinary albumin to creatinine level of $966.4 \mathrm{mg} / \mathrm{g}$., urine protein of $2+$, and a urinary protein excretion rate of $808.4 \mathrm{mg} /$ day. The C-reactive protein (CRP) level was normal, and the patient's $\mathrm{C} 3$ and $\mathrm{C} 4$ complement protein levels were 31 and $34 \mathrm{mg} / \mathrm{dL}$, respectively. The antinuclear antibodies (ANA) test was positive at a titer of 1:80, whereas tests for the anti-double stranded deoxyribonucleic acid (anti-dsDNA) antibody, antiextractable nuclear antigen antibody (ENA), and anti-neutrophilic cytoplasmic antibody (ANCA) were negative. Both ultrasound (US) and computed tomography (CT) showed lymph node enlargement at the neck, axillary fossa, and inguinal groove. One of the right axillary fossa lymph nodes was removed, and a pathological examination revealed reactive proliferation of the lymphatic follicle and hyalinized prominent vessels. In addition, there was partial fibrosis in the interstitial tissue. After evaluating all of the data, the patient was diagnosed with Castleman's disease (CD) and treated with five cycles of fludarabine $40 \mathrm{mg} \mathrm{d} 1-\mathrm{d} 3$ and cholera toxin (CTX) $0.4 \mathrm{~g} \mathrm{~d} 1-\mathrm{d} 3$. During the regular follow-up program, the US and CT scan showed a marked decrease in the size of the swollen lymph nodes, and no obvious recurrence was detected.

Three years later, the patient was admitted to our hospital again with complaints of fever that had been ongoing for two weeks. Laboratory tests were positive for ANA at a titer of 1:160. The test was also positive for the anti-dsDNA antibody (787 IU/ml); however, the patient tested negative for anti-ENA and ANCA. The C3 was 28, and the C4 was $45.5 \mathrm{mg} / \mathrm{dL}$. Additionally, the patient had a CRP level of $10.9 \mathrm{mg} / \mathrm{L}$ and a urinary protein excretion rate of $15,319 \mathrm{mg} /$ day. The patient was finally diagnosed with $\mathrm{CD}$ combined with SLE and treated with prednisone at $80 \mathrm{mg} /$ day for one week. This was followed by a decrease in the dosage to $36 \mathrm{mg} /$ day for another month. At that time, the ANA titer had decreased to 1:80, and the antidsDNA antibody was $185 \mathrm{IU} / \mathrm{ml}$.

Castleman's disease is a relatively rare disorder characterized by a massive nonmalignant tumor in the lymphoid tissues. Multicentric CD has a close relationship with several autoimmune diseases such as rheumatoid arthritis (RA), membranous nephropathy, and SLE. ${ }^{[1]}$ It also commonly presents

\footnotetext{
Received: October 27, 2012 Accepted: November 01, 2012

Correspondence: Xian Zhong, PhD. Zhejiang University College of Medicine, Jiefang Road 88\#, Hangzhou, China. Tel: 0086-571-87783868 e-mail: xzhong9@gmail.com

C2013 Turkish League Against Rheumatism. All rights reserved.
} 
with lymphadenopathies, autoimmune disorders, constitutional systemic symptoms, and recurrent infections, so an exact diagnosis is difficult to make based on the clinical and laboratory clues alone. ${ }^{[2]}$ Our patient presented with the hyaline vascular (HV) type of $\mathrm{CD}$ and then developed the autoimmune features of SLE.

Multicentric CD with systemic manifestations is usually treated with corticosteroids, interferon-alpha (IFN- $\alpha$ ), or cytotoxic immunosuppression, either with or without radiotherapy. ${ }^{[3,4]}$ In some recent reports, monoclonal antibody therapy, including anti-CD20 or anti-interleukin-6 (IL-6), has been used effectively in some cases. ${ }^{[5]}$ Due to kidney damage in our patient, we chose cytotoxic immunosuppression, and the patient responded very well over a prolonged period of time. After the SLE became active in this case, corticosteroid therapy was used to bring the symptoms under control. After one year of follow-up, the patient had recovered well and was being treated with oral prednisolone at a low dosage.

In conclusion, the diagnosis and therapeutic strategies of CD are great challenge for clinicians, because of its nonspecific histologic and clinical findings. Rarely, both CD and SLE could occur in the same patient. Therefore, close communication between the clinician and the pathologist is very important.

\section{Declaration of conflicting interests}

The authors declared no conflicts of interest with respect to the authorship and/or publication of this article.

\section{Funding}

This study was supported by the National Natural Science Foundation of China (81000945).

\section{REFERENCES}

1. Gohlke F, Märker-Hermann E, Kanzler S, Mitze M, Meyer zum Büschenfelde KH. Autoimmune findings resembling connective tissue disease in a patient with Castleman's disease. Clin Rheumatol 1997;16:87-92.

2. Herrada J, Cabanillas F, Rice L, Manning J, Pugh W. The clinical behavior of localized and multicentric Castleman disease. Ann Intern Med 1998;128:657-62.

3. Smir BN, Greiner TC, Weisenburger DD. Multicentric angiofollicular lymph node hyperplasia in children: a clinicopathologic study of eight patients. Mod Pathol 1996;9:1135-42.

4. Simko R, Nagy K, Lombay B, Kiss A, Minik K, Lukacs $\mathrm{VH}$, et al. Multicentric Castleman disease and systemic lupus erythematosus phenotype in a boy with Klinefelter syndrome: long-term disease stabilization with interferon therapy. J Pediatr Hematol Oncol 2000;22:180-3.

5. Casper C. The aetiology and management of Castleman disease at 50 years: translating pathophysiology to patient care. Br J Haematol 2005;129:3-17. 